\title{
THE ANALYSIS OF FINTECH ECOSYSTEM IN TURKEY
}

\author{
DOI: 10.17261/Pressacademia.2019.1162 \\ JBEF- V.8-ISS.4-2019(1)-p.188-197
}

\section{Selim Yazici}

Istanbul University, Faculty of Political Sciences, Department of Business Administration, Beyazit, 34349, Istanbul, Turkey selim@istanbul.edu.tr, ORCID: 0000-0001-7953-2496

To cite this document

Yazici, S., (2019). The analysis of fintech ecosystem in Turkey. Journal of Business, Economics and Finance (JBEF), V.8(4), p.188-197.

Permemant link to this document: http://doi.org/10.17261/Pressacademia.2019.1162

Copyright: Published by PressAcademia and limited licenced re-use rights only.

\begin{abstract}
Purpose - The purpose of this study is to analyze the dynamics of creating a wealthy FinTech Ecosystem. The state of the Turkish FinTech Ecosystem will be used as a case to determine the components of a healthy FinTech Ecosystem.

Methodology - This paper is designed on a self-reflection methodology. The author is the co-founder of FinTech Istanbul Platform, which is acting as a FinTech Hub to gather all the building blocks of the Ecosystem in Turkey since 2016. The reflections are based on the experience of the author gained both from Turkey and international hubs.

Findings - The main components of a FinTech Ecosystem consist of 8 elements: New technologies and tools that enable innovations; telecom and technology companies that create infrastructure for distribution; startups that create innovative business models; government and regulators that define the rules of the game; financial institutions that cooperate with startups; customers and users who benefit from innovations; investors, incubation centers and accelerators that enable both financial aid and space for innovators.

Conclusion - To create a wealthy FinTech Ecosystem, all players and stakeholders must work together and try to create synergy in order to sustain competitive advantage.
\end{abstract}

Keywords: FinTech, financial technologies, ecosystem, Turkey, ecosystem evaluation. JEL Codes: G21, O16

\section{INTRODUCTION}

Although we have met with FinTech (Financial Technology) concept within the last 10 years, it is possible to say that FinTech is highly sought after for investors, users and governments. In particular, the concepts such as digitalization and sharing economy brought about by the new economy have enabled the development and acceptance of financial technologies. Today, many countries consider FinTech startups and the environment they create as a potential for capturing foreign investments and know-how transfer, and make their best efforts to improve the ecosystem for the development of this field.

FinTech (Financial Technologies) is a dynamic field between the financial services industry and technology sectors where technology-focused startups innovate products and services currently provided by the traditional financial services firms. FinTech is reshaping the financial experience of millions of people and businesses around the world today, and has the potential to dramatically change our understanding of financial services tomorrow. On the other hand, FinTech innovation is an important component of economic development, where you can attract foreign direct investment and know-how, especially for emerging economies. FinTech startups have attracted more than USD 100 billions of investment within the last five years. It is vital for any country to create a dynamic, well-functioning ecosystem to flourish its companies and attract investments.

In this study, the importance of the concept of ecosystem, which defines the necessary infrastructure elements for the development of the FinTech area in a country, and the characteristics of the environment for the development of the ecosystem will be examined. The current situation of the FinTech ecosystem in Turkey will be used as an example. In this examination, firstly, the elements that make up a FinTech ecosystem within the framework of generally accepted approaches will be identified and then the current situation will be examined in terms of key factors such as demand, regulation, capital and human resources which are the drivers of this ecosystem. 


\section{FINTECH: DESCRIPTION AND EVOLUTION}

The term FinTech refers to innovation in financial services through the use of technology or the use of technology to make financial services more efficient in areas, such as banking, insurance, or capital markets (Chishti, Barberis, 2016; Schueffel, 2016). This definition actually refers to digital transformation and restructuring for financial institutions. Delivering faster, flexible and personalized products to customers through innovation is the core of the FinTech. The financial services sector is one of the largest sectors and the user experience in financial services is changing with FinTech, while mobile technologies bring many opportunities for innovation and growth in the FinTech field (Wilson, 2017).

To understand the concept of FinTech, the development of financial technologies must first be understood. The first acquaintance with financial technologies can be traced back to the 1950s when Frank McNamara created a Diners Club card, which later emerged as a business model for card payment systems (many FinTech initiatives today build business models on payment systems) (Skinner, 2016). The development of ATMs in the 1960s has led to a greater sense of technology in the banking sector, perhaps for the first time the contact between customers and banks realized through technology. Later, the expansion of credit cards, the development of electronic fund transfers (EFT), the expansion of telephone and internet banking, the use of mobile phones and mobile devices and their unique technological innovations (sensors, cameras and smart features) have changed the lives of financial service users significantly. In particular, the expansion of the mobile phone has enabled people to make transactions independently of time and location. When the development of FinTech is examined, it is seen that, as one of the first places of use, African countries that use SMS technology first come to the forefront in contrast to the countries where smartphones are common. Vodafone's M-Pesa, a mobile phone based money transfer service by SMS, launched in Kenya and Tanzania in 2007, is the most significant part of the history of FinTech. It allows users with a national ID card to deposit, withdraw, and transfer money easily with a mobile device. M-Pesa has expanded to Afghanistan, South Africa, India, and Eastern Europe (Blakstad, 2018).

It is possible to evaluate the effects of the 2008 Financial Crisis in many different dimensions. Some see it as a major destruction and others see it in terms of new opportunities. Undoubtedly, the economic and social impacts have had a profound impact on both the welfare of countries and the way of life of the societies. The most important feature of the 2008 crisis in terms of financial services sector was the focus on the risk policies and capital adequacy of banks' attention with the penalties and heavy regulations imposed on the banks. This naturally led banks to allocate more time and resources to internal processes, risk management and compliance, but less time to customers who expect more and more services (Arner, Barberis, Buckley, 2015). One of the important consequences of the 2008 Financial Crisis was the shaking of the trust of bank customers to banks. The environment created by many factors such as the decrease in the lending of banks due to the risk policies that changed after the crisis, the development of the internet and sharing economy and the use of smart devices in financial activities in the same period led to the emergence of FinTech startups.

With the support of technological innovations, FinTech startups, aimed at facilitating the lives of users in financial transactions, have been invested more than USD 100 billion globally between 2014-2018 according to CB Insights data. Until 2018, 39 FinTech startups worldwide have been rated as "Unicorn", by exceeding USD 1 billion in valuation (CB Insights, 2019). These and similar figures show the value given to FinTech startups in the economy on a global scale. However, in order to better evaluate the added value created by financial technologies, firstly, it is necessary to understand the ecosystem created in the financial technology field.

\section{FINTECH ECOSYSTEM}

The concept of ecosystem, as similar to biological systems, has been gaining interest in the management literature within the scope of the "system approach" for many years. Ecosystem refers to the environment in which living organisms survive and the systems that maintain continuity, namely the "natural environment", which expresses the interrelationships between living and non-living environments surrounding these organisms. This system is based on various balances and continues to operate and maintain as a result of close and mutual interactions with each other. The negativity experienced in any element of this natural balance affects all the elements of the system as required by the systems approach (Micklin, Poston, 1998). Disruption of natural balance is the biggest threat to the ecosystems. Life in ecosystems continues with energy flow and nutrient cycles. Management scientists, inspired by biological systems, described businesses as living organisms and their environments as ecosystems and tried to explain businesses in economic order in this way.

Based on this approach, understanding the FinTech ecosystem is important for the development of mechanisms to ensure the survival and growth of the ecosystem. Therefore, in the continuation of the study; the importance of the FinTech ecosystem, players of ecosystem, relationships between them, growth and competition strategies will be examined. 


\section{COMPONENTS OF A FINTECH ECOSYSTEM}

There are elements in an ecosystem, each of which works independently, but cannot survive without the interactions between them. Without interaction, the ecosystem loses its power and competitiveness falls. Therefore, the power of the ecosystem is dependent on the nature of the interactions and synergies between the elements but not only the sum of the powers of each element. To understand the dynamics of an ecosystem, it is necessary to examine the FinTech ecosystem players, their roles and their interdependencies first. The first question that comes to mind here is whether this ecosystem will change from country to country. Research shows that the structure of the ecosystems are very similar in every country. What distinguishes is the "climate" in which this structure is located. The power and competitiveness of this ecosystem changes as the climate changes. There are many studies attempting to identify FinTech ecosystem players and their roles in a country (Chishti, Barberis, 2016; Nicoletti, 2017; Arjunwadkar, 2018; Blakstad, Allen, 2018; Gupta, Tham, 2019). Based on these studies, it is possible to group the factors that make up the FinTech ecosystem in a country under eight main headings:

\subsection{New Technologies and Tools}

In the emergence of the FinTech ecosystem, new technologies, new economic approaches and new tools come to the fore. In particular, the development of mobile and wearable technologies and the emergence of business models that facilitate their adaptation to the financial field through changing socio-economic approaches (such as Behavioral Finance and Sharing Economy) have had an important role in the emergence and development of the ecosystem. Today, many softwares such as machine learning, artificial intelligence, chatbot, robot consultants (Sironi, 2016) and blockchain increase the variety of products and services offered in the field of financial technology (Thompson, 2017).

\subsection{Telecom and Technology Companies, Social Media and Internet Platforms}

The most important facilitators for understanding and using new technologies were, of course, telecom and technology companies that created an infrastructure for the use of these technologies through mobile devices. The facilitating and supporting effect here is provided by the internet platforms or social media tools with their assets. Today, companies such as Google, Apple, Facebook, Amazon are called "GAFA Bank" (inspired by the initials of the companies' names) with the opportunities and technologies they have, and by reversing the FinTech concept, they can cause the concept to evolve as "TechFin" with the introduction of technology companies into the financial field (Gupta, 2019).

\subsection{Startups}

These are the firms that provide solutions to the users with their innovative business models and by adapting the opportunities offered by technology, digitalization and mobile technologies to the financial field. One of the key players in the field of financial technology is the startups, whose basic features can be explained by the "LASIC Principles" (Low Margin, Asset Light, Scalable, Innovative, Compliance Easy), their ability to be established with a small capital, agile structures, innovative and rapid solutions, and with their high growth potentials (Chuen, Teo, 2015). Important factors in the emergence of startups are: entrepreneurs' knowledge of the sector, understanding the needs and pains correctly, providing a good business idea appropriate to the needs, having qualified human resources in teams, thinking globally (thinking of a global product), financial information, good understanding of the regulations and an adequate business model (Gimpel, Rau, Maximilian, 2018).

\subsection{Government and Regulators}

Perhaps the most important player in the ecosystem is the government. It is the government that constitutes the bodies providing the financial infrastructure, the structure that determines the rules of the game and determines the conditions of competition by enacting regulations. The most important role of the government arises in the stage of climate formation. Policy-making and the understanding of the FinTech concept by the relevant institutions of the state can make it a window of opportunity (Arner, Barberis, Buckley, 2017).

As discussed earlier, FinTech area is one of the largest investment areas in the world. Therefore, prioritizing this issue in a country's development plan and creating policies and strategies accordingly, create new opportunities for countries to directly attract foreign capital. Today, many developed and developing countries have taken FinTech as one of their priority areas among their development policies, and have managed to attract startups and investors to their countries by creating an appropriate investment climate with their approaches and regulations. 


\subsection{Financial Infrastructure Providers}

They are the institutions that are established by the government for the effective operation of the financial system. At the same time, they are the policymakers, regulators, supervisors that are maintaining the infrastructure of the financial system (Engel, 2015).

\subsection{Financial Institutions}

Banks, insurance companies, and capital market intermediary institutions are the major actors of the financial system. These institutions refer to the old, known and trusted institutional structures that have historically created the financial system, which are large, slow-moving in nature, working within the framework of certain principles. Many of these counted up to the 2008 Financial Crisis. However, with the 2008 Financial Crisis, the loss of confidence in the financial system caused some of these structures to disappear and some of them caused serious restructuring. These organizations act as the key players in the FinTech ecosystem by collaborating or partnering with startups (Alt, Beck, Smits, 2018).

\subsection{Customers and Users}

When the concept of customer is mentioned, more "business to business (B2B)" customers are perceived on the corporate scale. Today, however, the government can become an important FinTech user due to the services it offers and can be among the customers of startups. Today it is possible to see startups that develop cooperation with the government in many countries. Individual users (B2C) are perhaps the most important actors in the emergence of the FinTech field with their desire, need and behavior models (Chishti, Barberis, 2016). Here, the correct determination of users' wishes, needs and behavior models, form the essence of the innovative business model to be created. But, this requires a sociological perspective and understanding.

\subsection{Investors, Incubation Centers and Accelerators}

The importance of financial resources for the emergence and growth of an enterprise cannot be denied. Investors come to the forefront in obtaining financial resources. Today, it is possible to see different types of investors for every stage of the startups. While angel investors can be a significant investor, venture capital (VC) investors and corporate investors (CVC) can be used to provide the funds needed by enterprises at different stages.

In addition to investors, there are incubation centers and acceleration programs that make startups ready to attract investment starting from the idea stage (seed investment) (Brooks, 1986). Especially in the FinTech vertical, it is possible to come across many acceleration programs around the world. In such structures, the idea in the entrepreneur's mind is matured, tested and structured within a business model in a systematic way. In this way, enterprises that are able to do business are brought together with investors and investments are made in line with the wishes and needs of both parties. These structures can be established within the framework of a business model as well as with the support of the government can be established in Technoparks, Technology Transfer Offices of Universities (Jamil, Ismail, Mahmood, 2015). Today, it is possible to see the incubation centers established by financial institutions (such as banks) for their own purposes as well.

It seems possible to consider each of the ecosystem components mentioned above as independent components. However, given the interactions and synergies between them, it is possible to see that they are an integral part of a whole and the added value they will create for the country.

\section{GENERAL EVALUATION OF FINTECH ECOSYSTEM IN TURKEY}

In addition to developed countries, countries such as India, Singapore, Bahrain, Abu Dhabi, Dubai, Kazakhstan and Malaysia have started to make serious investments to attract FinTech startups to their countries. These countries have positioned themselves as "Financial Technology Centers", aiming to capture the attention of both FinTech startups, innovations and investors. Nowadays, attracting investment and ensuring its continuity is a strategic issue for every country. The current situation of foreign direct investments in the world economy is clear. Investments in traditional industries are now being replaced by high-growth technology investments. Therefore, among the competitive strategies of countries, FinTech occupy a priority position.

There are many studies evaluating whether countries are attractive in terms of financial technology investments. In a survey conducted by the Global FinTech Hubs Federation (GFHF) and Deloitte (Deloitte, 2017), 44 financial technology centers (Hubs) around the world were evaluated and scored with a system based on objective criteria for each Hub. Turkey was also evaluated for the first time in this report and achieved a low score. 
According to the Startups. Watch (Startups. Watch data, there are over 250 startups operating in 13 different verticals in the FinTech field in Turkey as of October 2019 (Figure 1).

Figure 1: Turkish FinTech Ecosystem Map (2019)

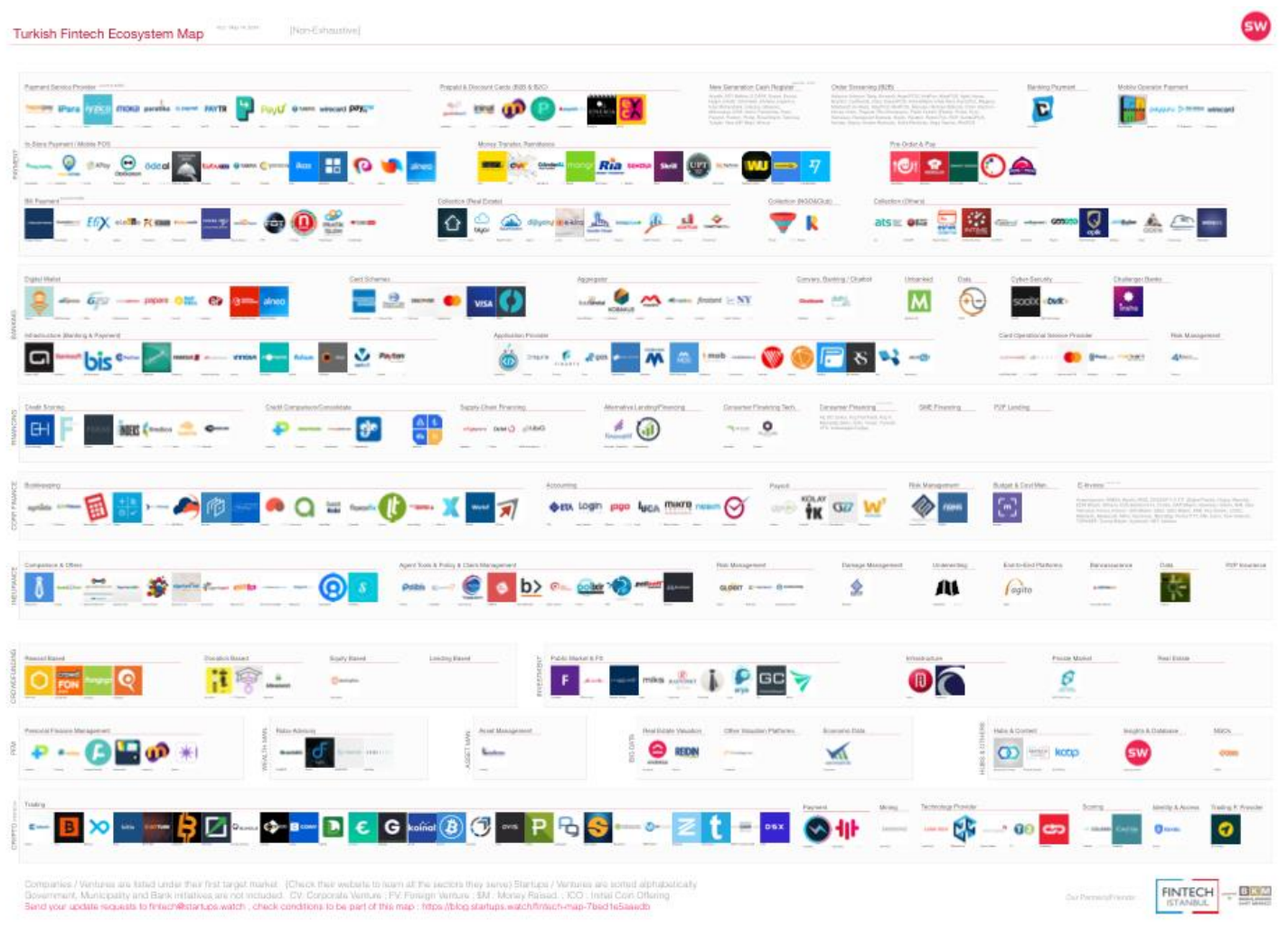

This paper is based on self-reflection research methodology. The author is the co-founder of FinTech Istanbul, a platform launched in 2016, acting as a Hub, aiming to bring together all the players in Turkish FinTech space and try to link them to global developments. With the experience and knowledge gained from FinTech Istanbul experience, the evaluation will be made in terms of both the ecosystem components and by using objective criteria. A Hub's strengths and weaknesses are heavily dependent on the issues such as regulation, customer proximity, expert human resources, the potential for attracting foreign startups, innovation culture, and government support. It is possible to say that they are the key elements that support the building blocks of a healthy ecosystem. Consequently, the effects of these elements will be taken into consideration when making the following assessment.

\subsection{Technological Developments, New Tools and Methods}

New technologies and tools are spread all over the world with globalization thanks to the inventions and technological developments in the world. What is important here is the use and development of these in line with the needs in the country. The most important technology in the field of FinTech is "mobile" technologies. Especially through smartphones, all financial transactions are carried out through the online channels of financial institutions, making it easier for users to make transactions by taking advantage of time and space without going to the bank. Apart from these, the development of card payment systems, wearable technologies, Internet of Things (IoT), Personal Assistants (such as Alexa, Siri, Bixby), Chatbots, Artificial Intelligence and Robotics Process Automation (RPA) software and applications are developed and used by startups in Turkey. One of the important elements here is to combine these new technologies and tools with the innovation culture in the country and turn them into commercial products. The closer the entrepreneurs are to the customers, the more they can analyze their wishes, needs and experiences from a sociologist's point of view, the more they produce products and services with high added value and increase their profitability.

\subsection{Infrastructure Providers and New Players in the Industry (TechFin)}


Telecom Operators provide the most important infrastructure enabling the use of mobile technologies. Apart from these, social media, internet platform companies, e-commerce companies and technology producing companies (such as Google, Facebook, Apple, Amazon) have started to focus on their financial needs by using the digital power of their customers. The point that gains importance here is the companies that produce solutions in order to facilitate the purchasing experience of the customer by entering between the customer and the shopping point.

The companies operating in this field in Turkey try to facilitate online payments and offer payment options (such as credit offering, installment, installment skipping) thanks to their cooperation with banks. In Turkey, telecom operators and ecommerce companies have seen the gap in the payment field and have started to offer online payment opportunities to a high number of customers. Therefore, such structures have begun to become "platform companies" by offering different combinations and to create their own ecosystems. In this way, these structures that enter the sector as new and powerful players are defined as "TechFin", that is, the entry of technology companies into the financial world (Skinner, 2016). Alibaba, Amazon and Apple are the most important examples of this globally.

\subsection{Status of FinTech Startups}

As shown in Figure 1, FinTech startups in Turkey operate in 13 different verticals. These are areas such as payments, banking, finance, corporate finance, insurance, crowdfunding, investment, personal finance management, asset management, big data, hubs, blockchain and crypto coins. Thanks to their innovative business models, they are able to offer products and services that are more flexible, faster, more cost-effective and more suitable to customer expectations than the corporate structures.

These startups should be considered together with the competencies of the entrepreneurs, their innovative approaches to the business model and the competencies of the teams they work with. In other words, the intellectual capacity of startups should be evaluated in terms of human resources. Generally, when human resources are mentioned, quality, quantity and costs emerge. The universities and other educational institutions play a key role in the development of this human resource.

The vast majority of startups today are software-oriented technology startups. More specifically, the FinTech field refers to a combination of technology, software and finance knowledge in a very specific field, such as financial technologies. Therefore, it is becoming increasingly difficult and costly to find human resources specifically trained in this field. Universities in Turkey have not yet established specialized programs in a field such as Financial Technology. Platforms such as "FinTech Istanbul" aim to close this gap with the programs they create in the sector. Therefore, Hub structures in the country play an important role in raising human resources as well as financial institutions.

Many financial institutions in Turkey support the entrepreneurship and creativity skills of their employees and support their efforts in developing new products through corporate entrepreneurship programs. In this sense, considering the quality, quantity and cost criteria of human resources, it should be considered that the country will become a center of attraction in terms of attracting FinTech startups. One of the best examples of this is the annual "Startup Istanbul" event held in Turkey. Every year, many startups in our region and close geographies apply to this event and look for opportunities to expand on a global scale thanks to the business models they develop. In this sense, especially Istanbul has started to become an attraction center for those startups.

\subsection{The Attitude of Financial Institutions}

Financial institutions are important players in the FinTech ecosystem. The "win-win" environment created especially by the cooperation with FinTech startups play an important role in the growth of the sector. However, as seen in every country, FinTech startups were seen as a competitor to banks at the beginning in Turkey. While banks did not want to give their shares, FinTech startups were trying to enter to market with their customer-oriented, innovative approaches. Nicols (2016) expresses this approach with the "Banker's FinTech Grief Cycle" (Figure 2).

Figure 2: The Banker's FinTech Grief Cycle 


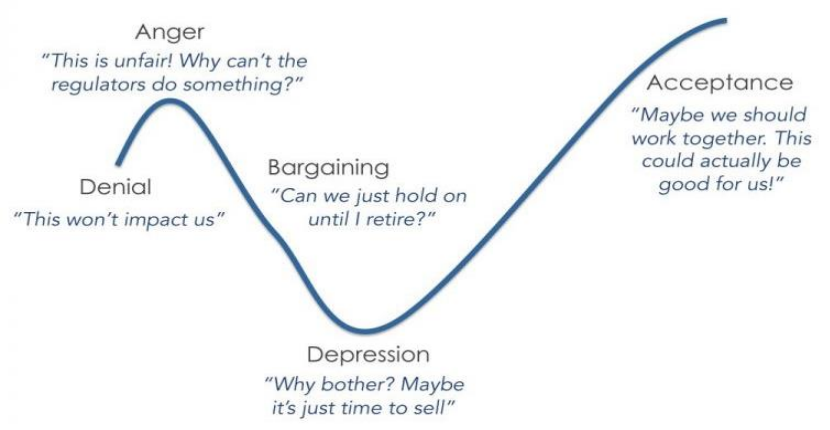

In his article published in 2016, J.P Nicols stated that the banks underwent a five-stage griefing process against FinTech startups. In the first stage, the process started by "denying" the existence of FinTech startups and their contributions to the sector and then turned into "anger" and tried to take more aggressive measures; after the "bargaining" between banks and FinTech startups to work around the problem with temporary solutions. In the "depression" stage, the idea that the sector is no longer profitable and that the deal is meaningless takes the banks and, in the end, the banks "accept" the situation and inevitably set sail for partnerships that will benefit both themselves and the sector (Nicols, 2016).

The situation has progressed in a similar way to Nicols' cycle in Turkey. FinTech-Bank relations in Turkey can be dated back to 2013. Initially, big banks provided superiority in the sector with their technology companies and the digital channels they developed thanks to them. Starting from online payment systems and virtual POS areas, FinTech startups have entered the fields that banks cannot realize, cannot enter or are not willing to enter with fast, innovative methods and customer experience. Nowadays, we see that even though the level is low, FinTech startups in Turkey have entered into a process of cooperation with banks.

\subsection{Government Perspective and Infrastructure of Financial System}

Here, the government's approach is very important. FinTech has entered into the financial policies and economic development models of many countries. UK, USA, Canada, Switzerland, Germany, the United Arab Emirates, Bahrain, Singapore, Malaysia and China have developed their state policies on FinTech, integrated them with laws and regulations, and show themselves as a center of attraction for attracting all startups in this field. Therefore, these countries have entered into a competition. It is known that FinTech has attracted more than 100 billion dollars in the world between 20142018. Therefore, it can be considered as a Foreign Direct Investment. Government needs to show the investors that there is a friendly environment in which to invest. For a long time, FinTech investments flowed to UK. What the fate of these investments will be after Brexit remains as a discussion topic. Many European counties are trying to get a share of this pie by trying to create an attractive environment of trust both by the regulations and the economic and political conditions of their countries.

When evaluating an area where finance and technology meet, such as FinTech, it is not enough to consider only the relationships between banks and enterprises. In this field of play, it is necessary to evaluate the infrastructure players of the financial system and their relations with the sector. In the financial sector, the infrastructure of the Banking Regulation and Supervision Agency (BRSA), The Central Bank of Turkey (CBRT), the Capital Markets Board (CMB), the Ministry of Treasury and Finance, the Revenue Administration (GIB) and the Financial Crimes Investigation Board (MASAK) regulate the institutions and organizations that constitute the infrastructure of the financial services sector in Turkey. Therefore, it is necessary to understand their working principles and reflexes while operating in this field. In short, it is not possible to operate in this field without knowing and understanding the rules of the game (regulation).

The priority of government institutions in this field is the security of the system and consumers. It is possible to address trust in two dimensions: Financial Trust and Information Security. Users of FinTech services first want to be sure that FinTech companies they are entrusting money with or FinTech companies with whom they are partnering are financially secure. Thus, they believe that they can easily benefit from their services. On the other hand, consumers, in particular, attach great importance to the security of personal data that FinTech companies hold. These two issues are regulated by Law No. 6493 and its sub-regulations for payment services, e-money services and system operation in Turkey. Law No. 6493 obliges payment and e-money institutions and system operators to obtain operating licenses. This requirement also necessitated the compliance with certain financial, process and technological criteria.

The amendments introduced by Law No. 6493 increased confidence in the sector and created an obstacle for the relatively small institutions that wanted to provide payment and e-money services. It is clear that the right height of the barriers 
created by the Law is critical for the size and reliability of the sector. In many countries, FinTech works with many different regulations. For example, in the area of Activity Permit (Licensing), which is a critical issue, countries (such as England, Lithuania, Estonia) issue different types of licenses for different fields of activity. This makes these countries more attractive for companies to carry their operations.

With the initiatives of BRSA, Central Bank, CMB, Treasury and Finance Ministry and Presidency Finance Office in the last two years, developments in the field of FinTech have been brought to the agenda of Turkey. The results of these efforts are included in the $11^{\text {th }}$. Development Plan. This shows that FinTech has entered the agenda of the government.

\subsection{Customers and Demand}

Customers and users, namely the size of the demand in Turkey, with a population of over 80 million and widespread use of smartphones are becoming attractive for many sectors. Considering the fact that a significant portion of the population is unbanked or under-banked and that citizens need easily accessible financial instruments and solutions, the importance of the services offered by FinTech startups that make life easier becomes evident for the sector. With the products developed by FinTech startups, it is aimed to include the masses who do not have access to financial products; it is clear that it will create satisfaction in terms of financial inclusion and fiscal policy in Turkey (as seen in other examples in the world such as India) in terms of both the growth of the market and the registered economy.

On the other hand, corporations that make up another dimension of demand (SME's) use the products and services offered by FinTech startups. Here; market structure in the country, competition, consumer behavior, customer experience, opportunities, threats and new markets that may occur in the financial services sector should be evaluated. The intensity of smartphone penetration in our country, the increase in the amount of online shopping and the development of ecommerce have led to the intensification of the use of virtual POS and the development of payment systems for FinTech startups that produce solutions that fit the country's payment habits. As shown in Figure 1, most of the FinTech startups in Turkey operate in payment systems.

\subsection{Capital and Investments}

In the capital dimension; investors, government support and public funds are the most important issues for FinTech startups that have the potential to grow rapidly. In the field of FinTech, TUBITAK and EU funds become prominent as government and publicly funded support; however, FinTech companies in Turkey are more timid about these issues and are directed towards angel investors, venture capital and bank incentives.

The investment level is not as high as the sector deserves. According to Startups.Watch data, in 2018, approximately 12 million USD was invested in FinTech startups in Turkey. The first factor that makes it difficult to get investments for FinTech startups is the lack of adequate data about the FinTech sector and the second factor is cautious foreign investors about the current conjuncture of Turkey.

Lack of the number of investors in Turkey is another important problem. Banks play an important role especially in cooperation with FinTech startups. Therefore, banks have the resources to invest in startups. Banks can provide the capital needed by FinTech startups, while FinTech startups can support banks with innovative ideas and methods, opening up new markets and offering them new opportunities. Nowadays, corporations investing by establishing their own venture capital funds is called Corporate Venture Capital (CVC). In Turkey, banks such as Akbank, Is Bank and Fibabanka are able to develop cooperation models by investing in FinTech startups with their own corporate funds.

\subsection{Other Complementary Supports}

Incubation centers, acceleration programs, thematic techno-cities and Sandbox environments are of great importance for the development of the FinTech area. In the UK, the Financial Conduct Authority (FCA) initiated the "Project Innovate" and invited all institutions in the country to take a supportive approach. Similarly, the National Money Authority of Singapore (MAS) established the national Sandbox platform and identified the scope and conditions of operation. In both approaches, the aim is to increase the participation in the financial system by testing new technologies in an effective and safe environment for innovation. The Sandbox environment should be created in a way to support innovation in the FinTech field, to follow technological new practices, and to ensure that regulations are strengthened by the industry (Arlanian, Fischer, 2019).

Even though the Sandbox environment has not yet been implemented in Turkey, it is possible to see the launch of the Thematic Technopark initiatives through universities. It is possible to see the first example of this with the joint venture of Bogazici University and Borsa Istanbul. The establishment of thematic Technopark areas on FinTech in cooperation with universities and the private sector will contribute greatly to the training of human resources with sector knowledge and 
experience, to the cooperation of universities and industry, to the implementation of new projects in FinTech and to support entrepreneurs and entrepreneurship.

\section{CONCLUSION}

When academic studies and ecosystems in different countries in the literature were evaluated, it is observed that the weights or functions of the players in the ecosystem may vary according to the cultural and economic characteristics of the countries, but the thing that does not change is the linked functioning of all those players. The power of the ecosystem is created by the synergy between them.

In this study, the financial technology field which attracts a high amount of investments all over the world and the importance of FinTech startups in this field have been evaluated especially in terms of today's strategic elements such as national economy, attracting investment and know-how transfer. In this way, an analysis tried to be made in Turkey. In this evaluation, first of all, the components of the ecosystem are presented and then the current situation is evaluated in terms of key factors such as demand, regulation, capital and human resources which are the drivers of this ecosystem.

Today, in the financial world, the concept of FinTech changes the rules of the game. Increasing financial access on a national basis, increasing productivity through collaboration with startups, improving financial innovation and providing better service and user experience to customers, preventing informality in the economy, increasing financial inclusiveness, attracting global investment and know-how transfer can be considered as the most important opportunities that a country can gain by investing on FinTech. It is important to note that the most important role here depends on the FinTech ecosystem players and the synergy between them. Therefore, it makes more sense to see the power of the FinTech ecosystem in a country as the sum of the impact of the relationship (synergy) between them rather than the sum of the power of the individual players.

\section{REFERENCES}

Alt, R., Beck, R., Smits, M.T. (2018). FinTech and the Transformation of the Financial Industry. Electronic Markets. 28(3): 235-243. DOI: $10.1007 / \mathrm{s} 12525-018-0310-9$

Arjunwadkar, P.Y. (2018). FinTech: The Technology Driving Disruption in the Financial Services Industry. Boca Raton: CRC Press.

Arner, D.W., Barberis, J., Buckley, R.P. (2015). The Evolution of FinTech: A New Post-Crisis Paradigm?. University of Hong Kong Faculty of Law Research Paper, No. 2015/047. DOI: 10.2139/ssrn.2676553

Arner, D.W., Barberis, J., Buckley, R.P. (2017). FinTech, RegTech, and the Reconceptualization of Financial Regulation. Northwestern Journal of International Law \& Business. 37(3): 371-413.

Arslanian, H., Fischer, F. (2019). The Future of Finance: The Impact of FinTech, Al, and Crypto on Financial Services. Switzerland: Palgrave, MacMillan.

Blakstad, S., Allen, R. (2018). FinTech Revolution: Universal Inclusion in the New Financial Ecosystem. Switzerland: Palgrave, MacMillan.

Brooks, O. J. (1986). Economic Development Through Entrepreneurship: Incubators and the Incubation Process. Economic Development Review. 4(2): 24-29.

CB Insights. (2019). 2019 FinTech Trends to Watch. (Report).

Chishti, S., Barberis, J. (Eds.) (2016). The FinTech Book. Chichester: Wiley.

Chuen, D.L., Teo, E.G.S. (2015). Emergence of Fintech and the LASIC Principles. The Journal of Financial Perspectives: FinTech. 3(3): 1-17. DOI: $10.2139 /$ ssrn.2668049

Deloitte. (2017). A Tale of 44 Cities: Connecting Global FinTech: Interim Hub Review 2017. (Report).

Engel, J.S. (2015). Global Clusters of Innovation: Lessons from Silicon Valley. California Management Review. 57(2): 36-65. DOI: $10.1525 / \mathrm{cmr} .2015 .57 .2 .36$

Gimpel, H., Rau, D., Röglinger, M. (2018). Understanding FinTech Start-ups - A Taxonomy of Consumer-oriented Service Offerings. Electronic Markets. 28(3): 245-264. DOI: 10.1525/cmr.2015.57.2.36

Gupta, P., Tham, T.M. (2019). FinTech: The New DNA of Financial Services. Boston: Walter de Gruyter.

Jamil, F., Ismail, K., \& Mahmood, N. (2015). A Review of Commercialization Tools: University Incubators and Technology Parks. International Journal of Economics and Financial Issues. 5(Special Issue): 223-228.

Micklin, M., Poston, D.L. (Eds.) (1998). Continuities in Sociological Human Ecology. New York: Springer. 
Nicols, J.P. (2016). The Fintech Grief Cycle for Bankers. Retrieved from jpnichols.com: http://jpnicols.com/2016/07/12/fintech-grief-cyclebankers/

Nicoletti, B. (2017). The Future of FinTech: Integrating Finance and Technology in Financial Services. Switzerland: Palgrave, MacMillan.

Schueffel, P. (2016). Taming the Beast: A Scientific Definition of FinTech. Journal of Innovation Management. 4(4): 32-54.

Sironi, P. (2016). FinTech Innovation: From Robo-Advisors to Goal Based Investing and Gamification. West Sussex: Wiley.

Skinner, C. (2016). ValueWeb: How FinTech Firms are Using Mobile and Blockchain Technologies to Create the Internet of Value. Singapore: Marshall Cavendish Business.

Startups.Watch (2019). Turkish FinTech Ecosystem Map. Online: https://startups.watch/

Thompson, B.S. (2017). Can Financial Technology Innovate Benefit Distribution in Payments for Ecosystem Services and REDD+?. Ecological Economics. 139: 150-157. DOI: 10.1016/j.ecolecon.2017.04.008

Wilson, J.D. (2017). Creating Strategic Value through Financial Technology. New Jersey: Wiley. 